\title{
DIFFERENCES IN QUALITY OF LIFE ACCORDING TO THE LEVEL OF PHYSICAL ACTIVITY BETWEEN TWO GROUPS OF BASKETBALL PLAYERS IN THE WHEELCHAIRS
}

\author{
Evangelos Chatzilelecas ${ }^{1}$, Branimir Filipović ${ }^{2}$, and Lidija Petrinović \\ ${ }^{1}$ Elpida, Rodos, Greece \\ ${ }^{2}$ Croatian waters, Zagreb, Croatia \\ ${ }^{3}$ Faculty of Kineziology, Univerzity of Zagreb, Croatia
}

\section{SUMMARY}

The aim of the study was evaluation of quality of life according to the level of physical activity between two groups of wheelchair basketball players. We included 34 individuals divided into the two groups according to the level of physical activity during the week. Individuals in the first group had trainings two times per week (16 individuals) and in the second group had trainings three to six times per week (18 individuals). Differences between these two groups were measured in quality of life and level of physical activity. Results of discriminative analysis have shown that there is statistically significant difference in quality of life, and results of Student t-test have shown that there is also statistically significant difference in level of physical activity as well as total quality of life. Individuals, who were active three to six times per week according to the schedule, had better results in all variables of the quality of life.

Key Words: individuals with disability, motoric skills, regular training, sport activities.

\section{INTRODUCTION}

For long periods of time, disabled persons were marginalized and they were recognized only due to their disability. Other characteristics such as emotional, social or spiritual life as well as any kind of creativity were under recognized. They were considered physically and socially non functional. In last decades, there were a lot of studies evaluating different kind of disability and different kind of exercises.

Hensle (1982) has shown that disabled persons after proper medical treatment and rehabilitation should be considered as healthy persons with different kind of physical disability which is treated as condition, not as disease.

Group of authors (Brasile, Kleiber, \& Harmisch, 1991; Cox \& Davis, 1992; Martin, Eklund, \& Mushett, 1997; Martin \& Mushett, 1996) were in their studies evaluating not only sport results, but also social and physical aspects of life of disabled persons. They were evaluating functioning in private life, so- ciety, stress control, mood, general physical and psychical functioning as well as cognitive functioning.

Kinesiological activities can help to disabled persons to change their attitude and to improve their way of seeing themselves from "I am disabled person" to "I have some level of disability" (Poretta, 2004).

Regular sport activities in disabled persons, improve their quality of life as well as social status, independence, better organization of free time activities, improves self respect, enables faster and easier achieving of personal goals and high level of reintegration into the society (Campbell \& Jones, 2002; PetrinovićZekan, 2009; Williams \& Kolkka, 1998). These results in better organization of free time, as well as establishing new contacts and friendships resulting in higher levels of self-respect, self-confidence, stress control, anxiety and depression as well as improvement in cognitive functioning (Campbell \& Jones, 1994; Sherrill, Hinson, Gench, Kennedy, \& Low, 1990).

Schonherr, Groothoff, Mulder, and Eisma (2005) Tasiemski, Kennedy, Gardner, and Taylor (2005), and 
Wu and Wiliams (2001) have shown similar results when evaluating impact of different levels of sport activities on everyday functioning in persons with spine injuries.

There is no uniform definition for quality of life. Most of the authors are of the attitude that the quality of life is multidimensional and very complex term, it is s emotionally colored and therefore has strong subjective component (Manns, 1999).

Post and Noreau (2005) was using very often in his works term Quality of life - QOL, but still without unique definition. Stevens, Caputo, Fuller, and Morgan (2008) were evaluating impact of different levels of physical activity on quality of life in persons with spine injury (SCI). Quality of life was measured as well with the QWB questionnaire (Quality of WellBeing Scale), while the level of physical activity in persons with spine injury was measured with PASIPD scale (Physical Activity Scale for Individuals with Physical Disabilities). Results of these studies have shown high correlation between levels of physical activity and quality of life.

Ravenek, Ravenek, Hitzig, and Wolfe (2012) were evaluating estimated quality of life (QQL) in persons with spine injury according to the level of physical activity (PA) and showed strong correlation.

World Health Organization [WHO] (1993) defines Quality of Life as individuals' perception of their position in life in the context of the culture and value systems in which they live and in relation to their goals, expectations, standards and concerns. It is a broad ranging concept affected in a complex way by the person's physical health, psychological state, level of independence, social relationships, personal beliefs and their relationship to salient features of their environment.

Some authors concern happiness and satisfaction as main parameters for quality of life, therefore they have special place in evaluation of individuals. Other authors think that quality of life is more complex including beside these two elements also general physical and psychical health, cognitive functions private and social life functioning.

Wheelchair basketball is for a long time one of the most attractive sport games for disabled persons no matter the cause of disability is. These days there is a variety of competition in wheelchair basketball all around the world. Rules are the same as in standard basketball with modification for wheelchair usage. One of the limiting factors in this sport is level of the spinal injury because it affects the level of motoric skills as well as affection of lower extremities, trunk, upper extremities and respiratory functions.
Also, cognitive abilities and motivation are very important for achieving good results (Bohm, 1982).

Main goal of this study is to evaluate differences in quality of life in wheelchair basketball players according to the level of physical activity.

\section{METHODS}

We were evaluating quality of life according to different levels of physical activity in disabled persons playing wheelchair basketball.

Disability is the consequence of an impairment that may be physical, cognitive, mental, sensory, emotional, developmental, or some combination of these. A disability may be present from birth, or occur during a person's lifetime. Disability can also varies- progressive or regressive dynamics as well as reversible or irreversible despite treatment and rehabilitation. Disability is an umbrella term, covering impairments, activity limitations, and participation restrictions. Impairment is a problem in body function or structure; inactivity limitation is a difficulty encountered by an individual in executing a task or action; while a participation restriction is a problem experienced by an individual in involvement in life situations. Thus, disability is a complex phenomenon, reflecting an interaction between features of a person's body and features of the society in which he or she lives.

We included in our study disabled persons from Greece using wheelchairs in their everyday's life. There were 34 males ages 18 to 47 years $(M=28.3)$, playing wheelchair basketball at least for a 6 months. These individuals are active players from wheelchair basketball clubs also playing for national cup. In the first group were 16 included persons who train 2 times per week and in the second group were included 18 persons training 3-6 times per week.

Causes of the disability were classified as follows:

- Injury $75 \%,(n=24)$ in $65 \%(n=21)$ the cause was traffic accident, in 10\% $(n=3)$ consequence of fall down.

- Present from birth, $10 \%,(n=3)$

- Residual disability after malignant or infective central nervous system diseases - 15\%, $(n=4)$.

Study was performed for 5 months - started at the beginning of October 2012, and ended in February 2013.

We collected data in interview with wheelchair basketball players by means of standardized questionnaires. Questionnaire had 3 main parts. In first part we evaluated demographic data, personal data, disability data, professional data, education data and habits. According to Washburn, Zhu, McAuley, 
Frogley, and Figoni (2002) we included in second part of the questionnaire data about the type and level of physical activity for each individual. According to Cummins (2005) we included into the third part of the questionnaire data about the quality of life.

All persons were informed about the study before entering and volunteered.

We evaluated two main values as a result of summing different parameters. First value was total physical activity [TPA]. This value was subdivided into: stationary activity, activity in movement, light physical activity, moderate physical activity and vigorous physical activity. All individuals were assessing their physical activity daily and weekly according to the method of Washburn et al. (2002). as well as by Van der Ploeg, Streppel, van der Beek, van der Woude, Vollenbroek-Hutten, and van Mechelen (2007). Second value was total quality of life [TQL]; evaluation was performed according to Cummins (2005). Values were standardized for general population (McCabe \& Cummins, 1998), and for disabled persons (Cummins, 2001; Verri et al., 1999).
Statistical evaluation was performed by means of STATISTICA 7.0 package. Data were analyzed by means of descriptive statistics including main quantitative parameters. Normal distribution was tested by means of Kolmogorov-Smirnov test. Student's $t$-test was used for evaluation of differences in quality of life. For evaluation of differences between the groups for each variable, we used canonic discriminante analysis. Difference was presented as coefficient of canonic discrimination; statistical significance was tested by means of Bartllet's chi-square test. Impact of individual variables between the groups was calculated by correlation of individual variables with discriminate factor.

\section{RESULTS}

Analyses of the descriptive parameters coefficients for TPA as well as the TQL have shown high variety between minimal and maximal values (wide range) for both variables (Table 1).

\section{TABLE 1}

Analysis of the descripitve parameters - TPA and TQL.

\begin{tabular}{rrrrrrrrrrr}
\hline$n$ & $M$ & \multicolumn{1}{c}{$S D$} & \multicolumn{1}{c}{$M d n$} & \multicolumn{1}{c}{ Mo } & \multicolumn{1}{c}{ Min } & Max & \multicolumn{1}{c}{$\mathrm{R} a$} & $v$ & Skew. & Kurt. \\
\hline 34 & 19.17 & 11.02 & 16.57 & 8.00 & 6.33 & 54.50 & 48.17 & 121.40 & 1.46 & 2.32 \\
\hline 34 & 50.91 & 9.63 & 52.50 & 59.00 & 30.00 & 67.00 & 37.00 & 92.81 & -.41 & -.47 \\
\hline
\end{tabular}

Legend: $\mathbf{n}$ - number of inhabitants; $\mathbf{M}$ - mean; SD - standard deviaton; Mdn - Medina; Mo - Mode; Min - mnimum; Max - maxmum; Ra - Range; v - varianca; Skew. - Skewness; Kurt. - Kurtosis.

Results of Kolmogorov-Smirnov test have shown asymmetry in distribution for the total physical activity variable $(K-S=.18)$ which depends on subvariable "sport activities" as the main characteristic of the two different evaluated groups. One reason for the asym-

\section{FIGURE 1}

Kolmogorov-Smirnov distibution for TPA.

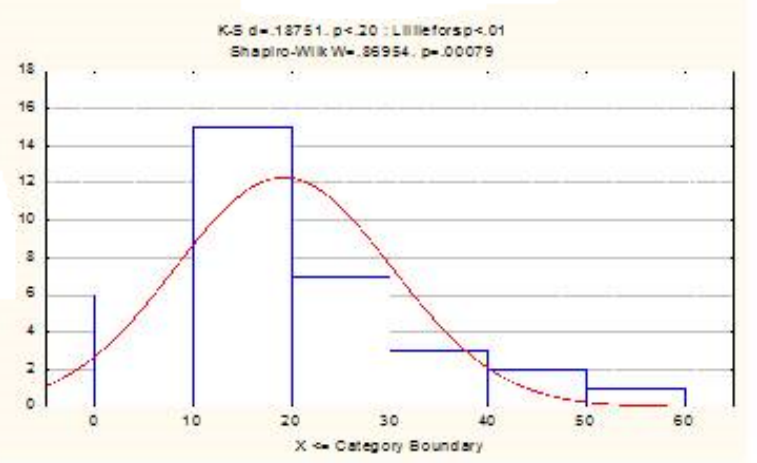

metry can also be wide range of results comparing to relatively small number of individuals (Figure 1).

Results of Kolmogorov-Smirnov test for total quality of life have shown also asymmetry, negative trend and platykurtic curve, but without statistically

\section{FIGURE 2}

Kolmogorov-Smirnov test TQL.

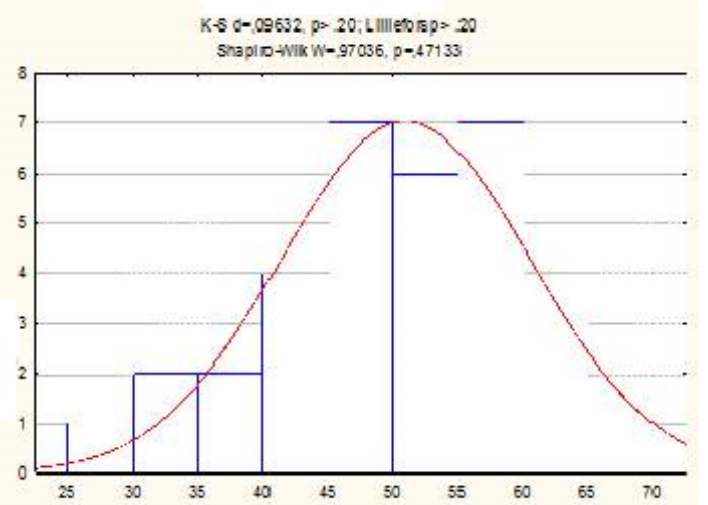


significant differences from normal distribution $(K-S$ $=.096)$, standard error 20\% ( $p>$.20) (Figure 2).

Results of the Student- $t$ test have shown statistically significant difference between 2 groups $(p<.01)$. Group 2 has statistically significant higher total physical activity level (3-6 times per week) than group $1(<2)$. Group 2 has better results; wheelchair basketball players who have higher level of physical activity (3-6 times per week) have better quality of life (Table 2).

\section{TABLE 2}

Student's t-test was used for evaluation of differences in quality of life - TPA and TQL.

\begin{tabular}{cccrcccccccc}
\hline & $n_{1}$ & $M_{1}$ & $S D_{1}$ & $n_{2}$ & $M_{2}$ & $S D_{2}$ & $t$ & $d f$ & $p$ & $F$ & $p$ \\
\hline TPA & 16 & 13.00 & 6.51 & 18 & 24.65 & 11.44 & -3.59 & 32 & $\mathbf{. 0 0}$ & 3.09 & $\mathbf{. 0 3}$ \\
\hline TQL & 16 & 45.81 & 10.50 & 18 & 55.44 & 6.06 & -3.32 & 32 & $\mathbf{. 0 0}$ & 3.00 & $\mathbf{. 0 3}$ \\
\hline
\end{tabular}

Legend: $\mathbf{n}$ - number of inhabitants; $\mathbf{M}$ - mean; SD - standard deviaton; $\mathbf{t}$ - Student- $t$ test; $\mathbf{d f}$ - Degrees of freedom; $\mathbf{F}$ - Fisher's F ratio; $\mathbf{p}$ - probability.

Canonic discriminant function analysis was used for evaluation of different subdomeins of the quality of life. Canonic correlation coefficient $(R=.63)$ reflects differences between the groups. Chi-Square coefficient $\left(\chi^{2}=14.23\right)$ was tested by means of Bartllet test and has shown statistically significant difference between the groups with $p$ value $<.05(p=.04)$. Wilk's lambda $(\Lambda=.61)$ together with Eigen-value (.65) is showing a relationship between the dependent groups and the independent variables (Table 3).
Relationship of the arithmetic means of each group in correlation to discriminative functions is shown in Table 4. Group 1 is on negative pole of the function $(-0,83)$, while the group 2 is on positive pole .of the function (.74). These results are showing that group 2 with higher level of TPA has higher TQL, while group 1 with lower levels of TPA has lower levels of total quality of life.

In Table 5, we presented different subdomains of the total quality of life domain: TQL -self confidence

\section{TABLE 3}

Eigen-value, canonic correaltion, coeffitient Wilks Lambda, values of the chi-square test, degrees of freedom and level of statistical significance.

\begin{tabular}{cccccc}
\hline Eigenvalue & $R$ & $\Lambda$ & $\chi^{2}$ & $d f$ & $p$ \\
\hline .65 & .63 & .61 & 14.23 & 7 & .04 \\
\hline
\end{tabular}

Legend: $\mathbf{R}$ - canonic correaltion; $\boldsymbol{\Lambda}$ - Wilks Lambda; $\boldsymbol{\chi}^{2}$ - Chi-square test; $\mathbf{d f}$ - Degrees of freedom; $\mathbf{p}$ - probability.

\section{TABLE 4}

Arithmetic means for the groups with discriminant factor.

\begin{tabular}{rr}
\hline$G \_1: 1$ & -.83 \\
\hline$G \_2: 2$ & .74 \\
\hline
\end{tabular}

(.71), TQL - family and interpersonal relations (.55), TQL - emotional well being (.49), TQL - physical health (.48) and TQL -social inclusion (.47), TQL achievements (.31), while others are not statistically significant. All of the previously mentioned variables are on the positive pole of the distribution.

All these results are showing that higher levels of physical activity have positive impact on total quality of life in all subdomains, with higher values for self confidence and family and interpersonal relationships, but also for the other variables.

\section{DISCUSSION}

In our study we have shown that the level of total physical activity has high impact on total quality of life in wheelchair basketball players. These results are in the correlation with the results of the previous studies showing positive impact of regular physical activity in general population, as well as in persons with different level of physical disability (Fiorilli et al., 2013 Hensle 1982; Lastuka \& Cottingham, 2015).

Evaluating different subdomains of total quality of life, we have shown that quality of life is multifac- 


\section{TABLE 5}

Correlation of individual variables with discrirminant factor - TQL.

\begin{tabular}{ll}
\hline TQL - standards & .30 \\
\hline TQL - physical health & .48 \\
\hline TQL - achievements & .31 \\
\hline TQL - family and interpersonal relations & .55 \\
\hline TQL - self confidence & .71 \\
\hline TQL - social inclusion & .47 \\
\hline TQL - emotional well being & .49 \\
\hline
\end{tabular}

torial and very complex individual perception. It is a broad ranging concept, depending on person's physical health, psychological state, level of independence, social relationships, personal beliefs and their relationship to salient features of their environment. These results are in positive correlation with previous studies (Brasile, Kleiber, \& Harmisch, 1991; Cox \& Davis, 1992; Martin, Eklund, \& Mushett, 1997; Martin \& Mushett, 1996; Wood 2013).

Level of Physical activity was shown in this study as the most important factor affecting total quality of life. Regular physical activity (wheelchair basketball with high intensity trainings) more than 3 times per week with moderate everyday physical activities is in direct positive correlation with quality of life. On the other hand, low levels of physical activity have negative impact on quality of life. These results are in correlation with previous works (Fiorilli et al., 2015; Ranevek et al., 2012; Stevens et al., 2008). There is of great importance that beside regular sport trainings more than 3 times per week, individual has moderate level of everyday physical activities (Granados et al., 2015; Lastuka \& Cottingham, 2015; de Witte, Hoozemans, Berger, van der Woude, and Veeger, 2015).

Previously mentioned physical activity in our study had strong impact on variables of the total quality of life subdomains: total quality of life-self confidence and total quality of life-family and interpersonal relations, with very close positive values, showing their importance and interactions. we found same positive trend for the other total quality of life subdomainstotal quality of life-emotional well being, total quality of life-physical health, total quality of life-social inclusion and total quality of life-achievements. In general population regular physical activity is very useful in prevention of chronic diseases (mostly cardiovascular and cerebrovascular), in population with different level of physical disability improves quality of life. One of the proposed underlying mechanism for these findings is secretion of endorphins during physical activity, regulating different neurotransmitter pathways of the emotional control in the central nervous system, as well as stimulating body metabolism resulting in physical well being and emotional well being, better stress control and development of healthy style of life. All these results have shown that regular physical activity results in better self confidence, as well as better functioning in family/personal life and reintegration in the society (Fiorilli et al., 2015; Ranevek et al., 2012; Stevens et al., 2008).

\section{CONCLUSON}

This study has shown that level of regular physical activity is very important for improvement of the quality of life in disabled persons. Wheelchair basketball was evaluated as regular sport activity of high intensity. In this special subpopulation of the persons with disability, we have shown that such king of activity 3 or more times per week can improve total quality of life, as well as different, very complex personal, physical, emotional, psychological, social subdomains, these results are in correlation with previous studies (Granados et al., 2015; de Witte et al., 2015).

\section{REFERENCES}

Böhm, W. (1982). Wörterbuch der Pädagogik

[Dictionary of Pedagogy]. Stuttgart, Germany, Kröner.

Brasile, F. M., Kleiber, D. A., \& Harmisch, D. (1991). Analysis of participation incentives among athletes with and without disabilities. Therapeutic Recreation Journal, 25(1), 18-33.

Campbell, E., \& Jones, G. (1994). Psychological well-being in wheelchair sport participants and non-participants. Adapted Physical Activity Quarterly, 11, 404-415.

Campbell, E., \& Jones, G. (2002). Cognitive appraisal of sources of stress experienced by elite male wheelchair basketball players. Adapted Physical Activity Quarterly, 19, 100-108. 
Cox, R. H., \& Davis, R. (1992). Psychological skills of elite wheelchair athletes. Palaestra, 8, 16-21.

Cummins, R. A. (2001). The subjective well-being of people caring for a family member with a severe disability at home. Journal of Intellectual \& Developmental Disability, 26(1), 83-100. doi: 10.1080/13668250020032787

Cummins, R. A. (2005). Moving from the quality of life concept to a theory. J. Intellect Disabil Res, 49(10), 699-706. doi: 10.1111/j.1365-2788.2005. 00738.x; PMid:16162114

de Witte, A. M., Hoozemans, M. J., Berger, M. A., van der Woude, L. H., \& Veeger, D. H. (2015). Do field position and playing standard influence athlete performance in wheelchair basketball? $J$ Sports Sci, 29, 1-10.

Fiorilli, G., Iuliano E, Aquino, G., Battaglia, C., Giombini, A., Calcagno, G., \& di Cagno, A. (2013). Mental health and social participation skills of wheelchair basketball players: a controlled study. Res Dev Disabil, 34(11), 3679_ 3685. doi: 10.1016/j.ridd.2013.08.023; PMid: 24012595

Granados, C., Yanci, J., Badiola, A., Iturricastillo, A., Otero, M., Olasagasti, J., ... Gil, S. M. (2015). Anthropometry and Performance in Wheelchair Basketball. J Strength Cond Res, 29(7), 1812-1820. doi: 10.1519/JSC.0000000000000817; PMid: 25536537

Hensle, U. (1982). Zur Auswirkung institutioneller und ausserinstitutioneller Bedinungen aur die Rehabilitaion [Effect of institutional and noninstitutional conditions in the rehabilitation]. In W. R. Minsel (Ed.), Brennpunkt der klinischen Phychologie (pp. 54-74). Munchen, Germany: Kosel.

Lastuka, A., \& Cottingham, M. (2015). Effect of adaptive sports on employment among people with disabilities. Disabil Rehabil, 26, 1-7. doi: 10.3109/09638288.2015.1059497; PMid: 26114627

Manns, P. J., \& Chad, K. E. ( 1999). Determining the relation between quality of life, handicap, fitness and physical activity for persons with spinal cord injury. Arch Phys Med Rehabill, 80(12), 1566-1571.

Martin, J. J., Eklund, R. C., \& Mushett, C. A. (1997). Factor structure of the Athletic Identity Measurement Scale with athletes with disabilities. Adapted Physical Activity Quarterly, 14, 74-82.

Martin, J. J., \& Mushett, C. A. (1996). Social support mechanisms of athletes with disabilities. Adapted Physical Activity Quarterly, 13, 74-83.
McCabe, M. P., \& Cummins, R. A. (1998). Sexuality and quality of life among young people. Adolescence, 33(132), 761-773.

Petrinović-Zekan, L. (2009). Povezanost tjelesne aktivnosti s kvalitetom rivivota osoba s invaliditetom [Connection of physical activity with the quality of life of people with disabilities]. Unpublished doctoral dissertation, University of Zagreb, Faculty of Kinesiology.

Porretta, D. (2004). Beginning a third decade. Adapted Physical Activity Quarterly, 21, 1-3.

Post, M., \& Noreau, L. (2005). Quality of life after spinal cord injury. J. Neurol Phys Ther, 29(3), 139146.

Ravenek, K. E., Ravenek, M. J., Hitzig, S. L., \& Wolfe, D. L. (2012). Assessing quality of life in relation to physical activity participation in persons with spinal cord injury: a systematic review. Disabil Health J., 5(4), 213-223. doi: 10.1016/j.dhjo.2012.05.005; PMid: 23021731

Schonherr, M. C., Groothoff, J. W., Mulder, G. A., \& Eisma, W. H. (2005). Participation and satisfaction after spinal cord injury: results of a vocational and leisure outcome study. Spinal Cord, 43(4), 241-248. doi: 10.1038/sj. sc.3101683; PMid: 15534622

Sherrill, C., Hinson, M., Gench, B., Kennedy, S. O., \& Low, L. (1990). Self-concepts of disabled youth athletes. Perceptual and Motor Skills, 70, 1093-1098. doi: 10.2466/PMS.70.3.1093-1098; doi: 10.2466/pms.1990.70.3c.1093; PMid: 2144624

Stevens, S. L., Caputo J. L., Fuller, D. K., \& Morgan, D. W. (2008). Physical Activity and Quality of Life in Adults With Spinal Cord Injury. J Spinal Cord Med., 31(4), 373-378.

Tasiemski, T., Kennedy, P., Gardner, B. P., \& Taylor, N. (2005). The association of sports and physical recreation with life satisfaction in a community sample of people with spinal cord injuries. NeuroRehabilitation, 20(4), 253-265.

Van der Ploeg, H. P., Streppel, K. R., van der Beek, A. J., van der Woude, L. H., VollenbroekHutten, M., \& van Mechelen, W. (2007). The Physical Activity Scale for Individuals with Physical Disabilities: test-retes reliability and comporasion with an accelerometer. J. Phys Act Health, 4(1), 96-100.

Verri, A., Cummins, R. A., Petito, F., Vallero, E., Montheath, S., Gerosa, E., \& Nappi, G. (1999). An Italiain-Australian comparasion of quality of life among people with intellectual disability living in the community. I Intellect Disabil Res, 
43(6), 513-522. doi: 10.1046/j.1365-2788. 1999.00241.x; PMid: 10622368

Washburn, R. A., Zhu, W., McAuley, E., Frogley, M., \& Figoni, S. F. (2002). The physical activity scale for individuals with physical disabilities: development and evaluation. Arch Phys Med Rehabil, 83(2), 193-200. doi: 10.1053/ apmr.2002.27467; PMid: 11833022

Williams, T. ,\& Kolkka, T. (1998). Socialisation into wheelchair basketball in the United Kingdom: a structural functionalist perspective. Adapted Physical Activity Quarterly, 15, 357-369.

Wood, A. (2013) Drawing disability in Japanese manga: visual politics, embodied masculinity, and wheelchair basketball in Inoue Takehiko's REAL. Cult Med Psychiatry, 37(4), 638-655. doi: 10.1007/s11013-013-9342-y; PMid: 24213739

World Health Organization. (1993). Rehabilitation after cardiovascular disease, with special emphasis on developing countries: Report of a WHO expert committee. WHO Technical Report Series 831. Geneva, Switzerland.

Wu, S. K., \& Williams, T. (2001). Factors influencing sport participation among athletes with spinal cord injury. Medicine \& Science in SporteExercise, 33(2), 177-182.

Received: April 13, 2015 Revision received: Jun 11, 2015

Accepted: Jun 25, 2015

Correspondence to: . Lidija Petrinović, Ph.D. Kineziološki fakultet Sveučilišta u Zagrebu Horvaćanski zavoj 15 10000 Zagreb Croatia Phone: 0038598317170 E-mail: lidija.petrinovic@kif.hr 